\title{
NSU
}

Florida

Nova Southeastern University

NOVA SOUTHEASTERN

UNIVERSITY

NSUWorks

College of Psychology: Faculty Articles

College of Psychology

9-1-1980

\section{Utility of Portable Breath Alcohol Testers for Drunken Driving Offenders}

Linda C. Sobell

Nova Southeastern University, sobelll@nova.edu

Robert VanderSpek

Dede Wallace Center

Pemmy Saltman

Dede Wallace Center

Follow this and additional works at: https://nsuworks.nova.edu/cps_facarticles

Part of the Psychology Commons

\section{NSUWorks Citation}

Sobell, L. C., VanderSpek, R., Saltman, P. (1980). Utility of Portable Breath Alcohol Testers for Drunken Driving Offenders. Journal of Studies on Alcohol, 41(9), 930-934.

Available at: https://nsuworks.nova.edu/cps_facarticles/68

This Article is brought to you for free and open access by the College of Psychology at NSUWorks. It has been accepted for inclusion in College of Psychology: Faculty Articles by an authorized administrator of NSUWorks. For more information, please contact nsuworks@nova.edu. 


\title{
BRIEF REPORTS
}

\section{Utility of Portable Breath Alcohol Testers for Drunken Driving Offenders}

\author{
Linda C. Sobell, ${ }^{1}$ Robert VanderSpek ${ }^{2}$ and Pemmy Saltman ${ }^{3}$
}

Summary. Participants in two countermeasures programs for drunken drivers found portable breath alcohol testers useful in making decisions about driving after drinking and said they would continue to use them if they were commercially available.

For the last several years, the prevailing countermeasure in the United States for drivers convicted of driving under the influence of alcohol (DUI) has been to send them to programs designed to provide them with information that will help them to avoid further arrests. Some of the information presented in such programs-e.g., how to estimate blood alcohol concentration (BAC), the meaning of the implied consent law, the legal definition of intoxication, clarification of laws relating to drunken driving-is predicated on the assumption that many drunken drivers are arrested because they lack the information necessary for making informed, responsible decisions about drinking and driving.

Many alcohol education programs teach DUI offenders how to estimate their BACs by using a standard estimation formula based on body weight and the amount of ethanol consumed over a specified time period. Regrettably, these formulas, of which there are several, are subject to considerable error across individuals. For instance, several factors (e.g., amount of adipose tissue, drinking histories, genetic differences) have been reported to affect the rates of ethanol absorption and metabolism in humans (1-5). Thus, using such formulas to

1 Clinical Institute, Addiction Research Foundation, 33 Russell Street, Toronto, Ontario, Canada M5S 2 S1.

2 Alcohol Programs, Dede Wallace Center, and George Peabody College of Vanderbilt University, Nashville, Tennessee.

3 Alcohol Programs, Dede Wallace Center.

Received for publication: 23 January 1979. Revision: 21 January 1980. 
determine whether a person is legally too intoxicated to drive could result in erroneous decisions.

One alternative to the use of BAC estimation formulas is to enable drinkers to determine their BACs objectively. For several years, law enforcement agencies have used a variety of breath alcohol testers to determine approximate BACS in the field. It seems reasonable to hypothesize that if people had access to breath alcohol testers, they might use them as a basis for making decisions regarding whether to drive after drinking.

Inexpensive portable breath alcohol testers are commercially available and have been used in clinical settings and treatment outcome studies to verify self-reported drinking behavior (6-8). While most of the portable testers are not sufficiently precise to provide legal evidence, one tester, the SM-6 Mobat, ${ }^{4}$ has been compared with legally acceptable breath testing devices and found to be relatively accurate at BACs of $0.08 \%-0.15 \%$, the most crucial range in determinations of legal drunkenness; errors in this range tended to be $\pm 0.02 \%$ or less $(7)$.

The present study investigated the utility of incorporating instruction in the use of portable breath alcohol testers into programs for DUI offenders.

\section{METHoD}

Subjects were referred by the Metropolitan Courts of Davidson County, Tennessee, to either an alcohol education-prevention program for first offenders $(N=94)$ or a treatment program for second and third offenders $(N=99)$. The education-prevention program consisted of weekly 90-min group sessions for 4 consecutive weeks. The treatment program for multiple offenders consisted of 1090 -min group sessions -8 consecutive weekly sessions and 2 booster sessions. ${ }^{5}$

The multiple offenders were slightly older (mean, 32.8 years; range, 2060 ) than the first offenders (mean, 30.8 years; range, 18-69). First offenders reported a mean of 11.9 years of education (range, 0-18) and multiple offenders a mean of 12.2 years (range, 5-19). Over $40 \%$ of the subjects in each program were married (42 of the 94 first offenders and 43 of the 99 multiple offenders), and slightly over $80 \%$ were Whites (76 and 82 , respectively), a racial makeup representative of that of the areas from which the subjects were referred. Men were grossly overrepresented in both groups, 85 of the 94 first offenders and 93 of the 99 multiple offenders being male. These percentages, however, were not unrepresentative of persons arrested for drunken driving in Tennessee (9). Multiple offenders reported a slightly

4 Mobat is the trade name for Sober-Meter Kit SM-6 manufactured by Lucky Laboratories, Inc., 7252 Osbun Road, San Bernardino, California 92404.

5 When this study began, the two booster sessions for the multiple offenders occurred 2 and 4 months after the eighth weekly session. After the study was partly completed, however, the curriculum was changed so that the two booster sessions occurred 1 and 2 months after the eighth session. Thus, participants in the multiple offenders' program were enrolled for between 4 and 6 months. 
higher gross monthly family income (mean, \$1142; range, \$0-4800) than did first offenders (mean, $\$ 856$; range, $\$ 0-2700$ ). This difference may be attributable to the fact that the multiple offenders had to be able to pay for a $\$ 200$ program, whereas the first offenders only had to be able to pay for a $\$ 40$ program.

Multiple offenders reported a mean of 2.23 Dur arrests. Although the alcohol education-prevention program was designed for first offenders, 11 participants reported more than 1 Dur arrest $(9$ reporting 2 arrests and 2 reporting 3 arrests).$^{6}$ Only 2 of the first offenders and none of the multiple offenders reported any alcohol-related hospitalizations. Similar percentages of subjects in each group reported at least 1 arrest for public drunkenness-19 of the first offenders and 25 of the multiple offenders. Finally, only 29 of the 99 multiple offenders felt that they had a drinking problem.

At the first meeting of the first and multiple offenders' groups, each subject was given two portable SM-9 Mobat breath alcohol testers, ${ }^{7}$ and the instructors explained and demonstrated their use. The subjects were also told that the breath testers were being evaluated for possible inclusion in the regular program curriculum. Because the treatment program extended over a much longer interval than the education-prevention program, participants in this group were given two additional SM-9 testers at the eighth meeting.

At the conclusion of the final group meeting, the subjects were asked to complete a questionnaire asking about their use of the testers over the course period, whether they might use similar testers in the future if they were commercially available, and whether they would recommend the testers to their friends.

\section{Results AND Discussion}

Since portable breath alcohol testers have not been readily or commercially available, it was not surprising to find that only 11 of our subjects had ever used such testers previously. Almost half (46 of 94) of the first offenders and one-third (32 of 99) of the multiple offenders reported that they had consumed enough alcohol on at least one occasion after they had received the testers to render them legally drunk.

While there was no explicit penalty or incentive for their use, 50 of the 99 multiple offenders 8 and 42 of the 94 first offenders reported trying the testers, many "just for fun" or "to see if they worked."

\footnotetext{
${ }^{6}$ Several judges made referrals to this program and some allowed multiple offenders who had never attended such a program to enroll.

${ }^{7}$ The SM- 9 tester is a variation of the SM- 6 tester, the major difference being that the SM-9 has a range of only $0.00 \%$ through $0.10 \%$ while the SM-6 records BACs up to $0.30 \%$. The SM-9 was used because a reading of $0.10 \%$ indicates that an individual's $\mathrm{BAC}$ is at least equal to or greater than the level generally considered indicative of legal intoxication and because it is slightly easier to use than the SM-6.

8 Nine multiple offenders' answers to the questions about their use of the breath testers had to be excluded from the analysis; two failed to answer the question, four gave incomplete or multiple answers and three tried the testers on their friends, not themselves.
} 
Of the 50 multiple offenders who used the testers, 25 explicitly stated that they used them to make a decision about whether they were legally too drunk to drive ( 7 of the 50 failed to answer this question). Ten of these 25 subjects reported that their breath testers indicated BACs in excess of $0.10 \%$, and only 1 of the 10 reported driving on that occasion. Further, 4 multiple offenders who had reported using the testers for other reasons registered BACs of $0.10 \%$ or more and also did not drive.

Of the 42 first offenders who used the testers, 14 reported using them to decide whether they were legally too intoxicated to drive ( 1 of the 42 failed to answer this question). Three of these 14 subjects had Bacs of $0.10 \%$ or more, and none chose to drive on that occasion. Thus, only 1 of the 17 ( 3 first offenders and 14 multiple offenders) who registered BACs legally indicative of intoxication actually drove on that occasion.

Many subjects in both groups who used the testers to determine whether they were legally too drunk to drive reported not driving, even though their BACS did not indicate they were legally drunk. Perhaps they were applying their own more conservative BAC standards.

Eighty-two of 92 first offenders and 78 of 99 multiple offenders said that they would use breath alcohol testers if they were readily available. High percentages of subjects in each program also indicated they would be willing to pay $\$ 1$ for each tester if they were commercially available. Further support for the potential utility of the testers is evidenced by the fact that $98 \%$ of the subjects in both programs indicated that they would tell their friends about the testers, and 93\% felt that their friends would be likely to use the breath testers for determining their own Bacs before driving.

Not surprisingly, when subjects had a longer period of time in which to try the testers (multiple offenders had 4 to 6 months, while first offenders had only 3 weeks), there was greater utilization, especially in relation to registering BACs of $0.10 \%$ or more. It is possible that many people are likely to abstain for a short period of time immediately after being convicted of driving under the influence of alcohol and being referred to a program. If so, the first offenders would have had less opportunity to use the testers.

Without question, drunken drivers who participated in an alcohol education-prevention program for first offenders or a treatment program for multiple offenders seemed to feel that commercially available breath testers would be useful not only for themselves but also for their friends. The utility of these testers seems to be based on their low cost and the fact that they provide immediate feedback. Although the testers are not legally valid breath alcohol testing instruments, they provide an easier and less variable method of calculating BAcs than do BAC estimation formulas. The fact that several subjects purchased additional breath test kits provides additional support for the usefulness of the testers. Countermeasures programs for drinking drivers should seriously consider making such testers readily available. 


\section{REFERENCES}

1. Mendelson, J. H. Ethanol-1-C ${ }^{14}$ metabolism in alcoholics and nonalcoholics. Science 159: 319-320, 1968.

2. Kater, R. M. H., Carulli, N. and Iber, F. L. Differences in rate of ethanol metabolism in recently drinking alcoholic and nondrinking subjects. Am. J. Clin. Nutr. 22: 1608-1617, 1969.

3. Vessel, E. S. Ethanol metabolism; regulation by genetic factors in normal volunteers under a controlled environment and the effect of chronic ethanol administration. Ann. N.Y. Acad. Sci. 197: 79-88, 1972.

4. REED, T. E. and KalANT, H. Bias in calculated rate of alcohol metabolism due to variation in relative amounts of adipose tissue. J. Stud. Alcohol 38: 17731776, 1977.

5. Utne, H. E., Hansen, F. V., Winkler, K. and Schulsinger, F. Alcohol elimination rates in adoptees with and without alcoholic parents. J. Stud. Alcohol 38: 1219-1223, 1977.

6. Miller, P. M. A behavioral intervention program for chronic public drunkenness offenders. Archs Gen. Psychiat. 32: 915-918, 1975.

7. Sobell, M. B. and Sobell, L. C. A brief technical report on the Mobat; an inexpensive portable test for determining blood alcohol concentration. J. Appl. Behav. Anal. 8: 117-120, 1975.

8. Sobell, M. B., Sobell, L. C. and VanderSpex, R. Relationships among clinical judgment, self-report, and breath-analysis measures of intoxication in alcoholics. J. Consult. Clin. Psychol. 47: 204-206, 1979.

9. Maistio, S. A., Sobell, L: C., Zelhart, P. F., Connors, G. J. and Cooper, T. Driving records of persons convicted of driving under the influence of alcohol. J. Stud. Alcohol 40: 70-77, 1979. 